\title{
RESPONSABILIDADE CIVIL MÉDICA NA EUTANÁSIA: ASPECTOS ÉTICO-LEGAIS ${ }^{1}$
}

MEDICAL CIVIL LIABILITY IN EUTHANASIA: ETHICAL AND LEGAL ASPECTS

Lara Ferraz de ARRUDA ${ }^{2}$

Rosângela Aparecida Vilaça BERTONI ${ }^{3}$

ISSUE DOI: $10.21207 / 2675-0104.2018 .745$

\section{RESUMO}

Esta pesquisa busca compreender melhor a questão da eutanásia e a responsabilidade civil médica, englobando relação jurídica e profissional. O médico, ao ser contratado pelo paciente, não se compromete a curá-lo, mas sim a agir conforme ética e regras de sua profissão. Nenhum profissional da saúde pode assumir obrigação de curar ou salvar o paciente, ainda mais quando o doente se encontra em estado grave ou terminal. No Brasil tanto eutanásia como ortotanásia continuam constituindo crime. A prática de eutanásia não está explícita no Código Penal Brasileiro, sendo configurada como homicídio.

Palavras-chave: Eutanásia. Morte. Bioética. Responsabilidade civil - médicos.

\section{ABSTRACT}

This research pursuit to improve understanding of euthanasia and medical civil liability including legal and professional relationship. When hired by patient, the physician makes no commitment to cure him,

\footnotetext{
${ }^{1} \mathrm{O}$ presente artigo sintetiza a monografia de conclusão da pesquisa, realizada para o Programa Interno de Bolsas de Iniciação Científica (PIBIC 2017-2018) da Faculdade de Direito de Franca (FDF), Franca/SP.

${ }^{2}$ Discente da Faculdade de Direito de Franca (FDF), Franca/SP. Bolsista do Programa Interno de Bolsas de Iniciação Científica (PIBIC 2017-2018).

${ }^{3}$ Graduada em Direito pela Faculdade de Direito de Franca (1982), mestrado em Direito Empresarial pela Universidade de Franca (2002) e Especialização em Direito Registral Imobiliário pela Universidade Esade-Espanha. Tem experiência na área de Direito, com ênfase em Direito Civil e assessoria jurídica. Advogada Militante.
} 
but act according to ethics and rules of their profession. No health professional can take obligation to cure or save the patient, even more when the patient is in serious or terminal condition. In Brazil, both euthanasia and orthothanasia, remain constituting crime, independently of arguments of physician. The practice of euthanasia is not explicit in the Brazilian Penal Code, being considered as homicide.

Keywords: Euthanasia. Death. Bioethics. Medical civil liability.

Atualmente, realizam-se estudos referentes ao fenômeno da morte e as atitudes do homem diante dela. É considerado tema multidisciplinar, abrangendo várias áreas do conhecimento. Essa pesquisa busca compreender melhor a questão da eutanásia e a responsabilidade civil médica, englobando a relação jurídica e profissional, pois ao se tratar de eutanásia, a responsabilidade dos médicos é de grande importância. A morte termina com a existência da pessoa natural; sob o ponto de vista jurídico, pessoa natural é aquela que tem personalidade jurídica, ou seja, possui aptidão para contrair direitos e deveres. O paciente em sofrimento, no seu estado terminal, ainda mantém a personalidade jurídica, pois ainda não faleceu. Lidar com a morte não é fácil. Sabemos que é a linha de chegada da vida humana. Ao estar frente a um paciente em estado terminal surgem incertezas de aspecto pessoal e sobre o tratamento ao próximo. Assim, a existência de inúmeras pessoas em leitos hospitalares, à beira da morte, por si só, justifica o estudo.

No ordenamento jurídico brasileiro há carência de normas específicas com relação à eutanásia. Por isso, esta pesquisa tem como objetivo apresentar e discutir, nos campos do Direito e Bioética, conceitos relacionados à eutanásia e também analisar a responsabilidade civil médica diante da eutanásia. Tendo em vista a situação em que o país se encontra, onde a responsabilidade profissional perde para interesses particulares e capitalismo, a discriminação é notável, mas em contrapartida, o crime de eutanásia não ocorre de forma indiscriminada.

A escolha do objeto de pesquisa foi baseada na admiração pelo Direito Civil e pela tentativa de apresentar respostas a questionamentos que indagam a sociedade acerca do tema abordado. No que diz respeito à metodologia, a presente monografia será desenvolvida com base em revisão de literatura incluindo livros, artigos, dissertações e processos.

Pode um profissional da medicina abreviar a vida de um paciente que ele julgue estar em estado terminal? Quais as sanções e penas 
atribuídas a esse profissional? Esta pesquisa pretende investigar as indagações acima, mas não pressupõe solução definitiva para o tema, apenas uma análise para melhor compreensão do mesmo.

\title{
2 DA RESPONSABILIDADE CIVIL
}

A responsabilidade civil relaciona-se a ideia de não prejudicar o outro. Podemos defini-la como aplicação de medidas ou punições, restituições ou ressarcimentos que obriguem alguém a reparar outrem que foi lesado por sua ação ou até mesmo omissão. É dever jurídico que recompõe o dano sofrido por alguém, imposto àquele que lesou, direta ou indiretamente, outrem. Nas palavras de Rui Stocco:

\begin{abstract}
A noção da responsabilidade pode ser haurida da própria origem da palavra, que vem do latim respondere, responder a alguma coisa, ou seja, a necessidade que existe de responsabilizar alguém pelos seus atos danosos. Essa imposição estabelecida pelo meio social regrado, através dos integrantes da sociedade humana, de impor a todos o dever de responder por seus atos, traduz a própria noção de justiça existente no grupo social estratificado. Revela-se, pois, como algo inarredável da natureza humana. (STOCCO, 2007, p.114).
\end{abstract}

Em seu sentido etimológico e jurídico, a responsabilidade civil está atrelada a ideia de contraprestação, encargo e obrigação. Porém, é necessário distinguir "obrigação" de "responsabilidade". A obrigação é sempre dever jurídico originário; a responsabilidade é dever jurídico sucessivo consequente à violação do primeiro (CAVALIERI FILHO, 2008). ${ }^{4}$

O que se prega no direito atual é que não se pode deixar a vítima de ato ilícito sem qualquer ressarcimento ou restituição, restaurando-se a sua moral e/ou o seu patrimônio. A responsabilidade do agente pode resultar da violação de normas morais e também de normas jurídicas, estejam elas separadas ou não. São considerados elementos formadores da obrigação de reparar outrem: a existência de ação ou omissão, o dano, a culpa e o nexo causal. A forma como se repara o dano da responsabilidade civil foi sofrendo alterações e transformações no decorrer da evolução jurídica.

\footnotetext{
${ }^{4}$ CAVALIERI FILHO, Sérgio. 2008, p.3.
} 
A origem da responsabilidade civil vem do direito romano e assim, não se cogitava o fator culpa na ocorrência de dano, diferentemente do que se estuda nos dias atuais, em que a responsabilidade civil se baseia nos três pressupostos: um dano, uma culpa do autor e a relação de causalidade entre esse mesmo dano e um fato culposo. Está relacionada à ideia de vingança e, consequentemente, de reações instintivas e brutais, e não de direito, porque naquele tempo não era, ainda, imperado o direito. Mesmo após o marco do direito romano, que foi o surgimento da Lei das XII Tábuas, ainda existia a Pena de Talião, mais conhecido como "olho por olho, dente por dente". Porém, o Estado com o decorrer dos anos, veio a intervir na aplicação dessa pena, atribuindo as penas de restituição.

Como ensina Pablo Stolze Gagliano e Rodolfo Pamplona Filho: "Um marco na evolução histórica da responsabilidade civil se dá, porém, com a edição da Lex Aquilia, cuja importância foi tão grande que deu nome a nova designação da responsabilidade civil delitual ou extracontratual" (GAGLIANO; PAMPLONA, 2003). ${ }^{5}$ Essa lei destacou-se por substituir a multa fixa por uma pena proporcional ao dano causado.

O Código Civil Brasileiro de 1916 se espelhou no Código Civil de Napoleão onde a culpa foi considerada um pressuposto da responsabilidade civil aquilina. ${ }^{6}$ Porém, essa teoria da culpa demonstrada na legislação francesa não foi capaz de abranger todos os casos concretos no decorrer do tempo, tendo assim que aprimorar e acrescentar outras teorias, o que ocorreu também no Código Civil Brasileiro. A legislação anterior baseia-se na teoria de responsabilidade civil subjetiva, ou seja, que exige prova da culpa ou do dolo do agente, com algumas exceções que presumem a culpa do causador do dano. Porém, com desenvolvimento da humanidade, novas teorias surgiram, propiciando proteção maior às pessoas lesionadas.

A teoria da responsabilidade civil objetiva fundamenta-se no princípio da equidade, o qual afirma que quem lucra com determinada situação deve responder pelos riscos e desvantagens resultantes. No Código Civil de 2002 há princípio da responsabilidade baseado na culpa do agente, como impõe o artigo 186, desse mesmo código, ao definir ato ilícito: "Aquele que por ação ou omissão voluntária, negligência ou imprudência, violar direito e causar dano a outrem, ainda que

\footnotetext{
${ }^{5}$ STOLZE GAGLIANO, Pablo; PAMPLONA FILHO, Rodolfo. 2003, p.11.

${ }^{6}$ GONÇALVES, Carlos Roberto. 2017, p.33.
} 
exclusivamente moral, comete ato ilícito." ${ }^{7}$ Pode-se considerar como sendo principal modificação de responsabilidade civil no Código Civil de 2002 mudanças sobre o que é considerado como atividades de risco ou perigosas.

\subsection{CULPA E RESPONSABILIDADE}

O Código Civil Brasileiro de $1916^{8}$ foi inspirado no Código Civil Francês, portanto alude a faute, ou seja, o erro, como o principal fundamento do dever de reparação do dano. Porém, devido à ambiguidade do termo, gera muitas discussões; alguns doutrinadores utilizam, para definir a culpa do agente, o aspecto subjetivo, enquanto outros, o objetivo.

Para tentar solucionar essa discussão, o legislador brasileiro considera ato ilícito como causa da responsabilidade civil, observado no artigo 186, do Código Civil Brasileiro de 2002. Assim, ao agir com negligência ou imprudência, ou até mesmo fazer omissão voluntária, terá como consequência reparação do dano. Desse modo, só é possível cogitar a culpa do agente se o resultado for previsível. Ao contrário, sendo imprevisível não se pode cogitar culpa alguma. Essa previsão da culpa é medida pelo grau de atenção exigido do homo medius. Porém, a culpa em si não se presume de uma forma geral, válida a todos os cidadãos; deve ser apurada em cada caso concreto. Portanto, a vítima de um dano só poderá pleitear ressarcimento de alguém se provar que essa pessoa agiu com culpa.

O artigo 186 do Código Civil Brasileiro de 2002 impõe como um dos elementos a imputabilidade, ou seja, livre vontade do agente. Para que o agente, ao praticar ato ilícito, seja obrigado a reparar aquele determinado dano causado a outrem, ele necessitará de pleno discernimento. Diz-se imputável o agente que é mentalmente são e desenvolvido. Portanto, se um cidadão não pode querer e/ou entender o que está fazendo, não pratica ato ilícito, não incorrendo assim, uma culpa daquele agente. ${ }^{9}$ Então, pode-se afirmar que um dano previsível e evitável para um, pode não ser igualmente considerado para outrem.

A responsabilidade civil legal ou objetiva é aquela que advém da prática de ato ilícito da violação do direito alheio e independe da culpa do

\footnotetext{
${ }^{7}$ MACHADO, Costa et al. 2016, p. 202.

${ }^{8}$ GONÇALVES, Carlos Roberto. 2017, p.33.

${ }^{9}$ GONÇALVES, Carlos Roberto. 2017, p. 35.
} 
agente causador do dano, se satisfazendo apenas com o dano em si e o nexo de causalidade. Foi adotada pelo Código Civil Francês, uma vez que com a Revolução Industrial determinadas atividades foram consideradas perigosas, sejam elas pela própria natureza ou até mesmo por determinação legal. Então, doutrinadores e juristas do final do século XIX, reconheceram responsabilidade do agente pelo simples risco que a atividade oferecia à população. ${ }^{10}$

No âmbito civil, nessa teoria denominada como objetiva ou de risco é obrigatória a indenização mesmo que não haja a culpa do agente, porque considera todo dano indenizável e deve ser reparado por quem a ele se liga por um nexo de causalidade, mesmo inexistindo a culpa, como leciona Agostinho Alvim (1980). ${ }^{11}$ A teoria do risco busca justificar a responsabilidade objetiva, porque, nela, em toda ação de uma pessoa há a criação de um risco para um terceiro. Portanto, fica obrigado a reparar o dano, mesmo que inexista a culpa. Como impõe o artigo 927, o Código Civil Brasileiro de 2002: "Haverá obrigação de reparar o dano, independentemente de culpa, nos casos especificados em lei, ou quando a atividade normalmente desenvolvida pelo autor do dano implicar, por sua natureza, risco para os direitos de outrem". A redação dessa norma jurídica possibilita ao judiciário uma ampliação dos casos de dano indenizável, como afirma Carlos Roberto Gonçalves (2017). ${ }^{12}$

A responsabilidade objetiva é usada em inúmeras leis sancionadas do ordenamento jurídico como a Lei de Acidentes de Trabalho, Lei n ${ }^{\circ}$ 6.938/81, ${ }^{13}$ Código de Defesa do Consumidor, entre outras. Pode-se notar, portanto, que a responsabilidade objetiva não descarta a subjetiva, contudo fica limitada. A culpa pode existir ou não, porém será irrelevante para configurar o dever do agente de indenizar aquele que foi lesado. Basta, portanto, que exista apenas uma relação de causalidade entre o dano e a ação do agente causador.

Responsabilidade civil subjetiva é aquela que engloba culpa stricto sensu e dolo. Fica caracterizado como culpa, quando o agente causador do dano atuar com imprudência, negligência ou imperícia. Já como dolo, quando o agente consciente e com sua própria vontade, pratica ato ilícito. ${ }^{14}$ Sabe-se que a culpa, na teoria clássica ou subjetiva, é

\footnotetext{
${ }^{10}$ SILVA, Wilson Melo da. 1962, p. 93.

${ }^{11}$ ALVIM, Agostinho. 1966, p. 237.

${ }^{12}$ GONÇALVES, Carlos Roberto. 2017, p. 52.

${ }^{13}$ MELLO, Cleyson de Moraes et al. 2016. Lei no 6.938/81

${ }^{14}$ GONÇALVES, Carlos Roberto. 2017, p. 48
} 
considerada fundamento da responsabilidade. Assim, não havendo a culpa do agente, não há responsabilidade do mesmo pelo dano causado. Então, para que tenha a indenização do dano causado é necessário que se comprove a culpa, o que, na sociedade moderna, algumas vezes não é possível. Portanto, na responsabilidade civil subjetiva, só é comprovada a responsabilidade do agente se houver confirmação de que ele agiu com dolo ou culpa. ${ }^{15}$

Leciona Carlos Roberto Gonçalves (2017): “Diz-se, pois, ser "subjetiva" a responsabilidade quando se esteia na ideia de culpa. A prova de culpa do agente passa a ser pressuposto necessário do dano indenizável. Dentro dessa concepção, a responsabilidade do causador do dano somente se configura se agiu com dolo ou culpa." ${ }^{16}$ Os casos de culpa presumida se enquadram na responsabilidade subjetiva do agente, tendo em vista que, se baseiam na culpa do causador, mesmo que essa seja presumida.

O Código Civil de 2002, artigo 186, ao definir “ato ilícito", adota Princípio da Responsabilidade com Culpa, tendo como fundamentos dolo e culpa para agente ser obrigado a reparar dano. Adota, em contrapartida, a Teoria do Exercício da Atividade Perigosa e o Princípio da Responsabilidade independentemente de culpa (vide artigo 927 desse Código).

\subsection{RESPONSABILIDADE MÉDICA}

A responsabilidade civil do médico é entendida pela formação de contrato entre ele e seu paciente. Portanto, é possível afirmar que teoricamente o profissional inexecute obrigação ao não obter a cura do paciente. Porém, afirma José de Aguiar Dias (1997): "o fato de se considerar como contratual a responsabilidade médica não tem, ao contrário do que poderia parecer, o resultado de presumir a culpa." ${ }^{.17}$ Essa responsabilidade enquadra-se na regra geral, portanto trata-se de responsabilidade civil subjetiva. Segundo afirma Delton Croce:

“(...) Se denomina responsabilidade médica situação jurídica que, de acordo com o Código Civil, gira tanto na órbita contratual como

${ }^{15}$ GONÇALVES, Carlos Roberto. 2017, p. 48.

${ }^{16}$ GONÇALVES, Carlos Roberto. 2017, p. 48.

${ }^{17}$ AGUIAR DIAS, José de. 1997, p. 296. 


\begin{abstract}
na extracontratual estabelecida entre o facultativo e o cliente, no qual o esculápio assume uma obrigação de meio e não de resultado, compromissando-se a tratar do enfermo com desvelo ardente, atenção e diligência adequadas, a adverti-lo ou esclarecê-lo dos riscos da terapia ou da intervenção cirúrgica propostas e sobre a natureza de certos exames prescritos, pelo que se não conseguir curá-lo ou ele veio falecer, isso não significa que deixou de cumprir o contrato". (CROCE, 2002, p.3). ${ }^{18}$
\end{abstract}

O médico, ao ser contratado pelo paciente, não se compromete a curá-lo, mas sim a agir conforme ética e regras de sua profissão. Assim, entende-se que a responsabilidade contratual pode ser presumida ou não, dependendo do que foi combinado por ambas as partes. Nenhum profissional da saúde pode assumir essa obrigação de curar ou salvar o paciente, por mais competente e renomado que seja, ainda mais quando o doente se encontra em estado grave ou terminal. A obrigação assumida pelo médico é obrigação de meio, como pode-se observar nas jurisprudências.

José de Aguiar Dias (1997) aponta que o objeto de contrato do médico não é a cura, mas sim a prestação de cuidados, conforme seu aprendizado. ${ }^{19}$ Então, o médico somente será responsabilizado se agir com imprudência, negligência ou imperícia e, assim, ficar comprovado. Como impõe o artigo $14, \S 4^{\circ}$, do Código de Defesa do Consumidor: "A responsabilidade pessoal dos profissionais liberais será apurada mediante verificação de culpa". Portanto, entende-se que a comprovação da culpa é imprescindível para jurisprudência. ${ }^{20} \mathrm{O}$ profissional liberal pode responder, também, por fato danoso que tenha sido praticado por terceiro, mas que este esteja sob sua responsabilidade e, não somente por um dano que ele mesmo cometeu, ou seja, um fato próprio.

Segundo o artigo $6^{\circ}, \mathrm{III},{ }^{21}$ do Código de Defesa do Consumidor, está obrigado ao fornecedor prestar todas as informações acerca do produto e do serviço, ou seja, o médico tem o dever de informar o seu paciente da maneira mais completa possível, estando, assim, ligado ao princípio da transparência. Esse princípio, encontrado no artigo 31, desse mesmo código, obriga o profissional na necessidade de fornecer informações completas, claras e precisas, "bem como sobre os riscos que apresentam à saúde e segurança dos consumidores".

\footnotetext{
${ }^{18}$ CROCE, Delton. 2002, p.3.

${ }^{19}$ AGUIAR DIAS, José de. 1997, p. 297.

${ }^{20}$ MELLO, Cleyson de Moraes et al. 2016. Artigo 14, $\$ 4^{\circ}$.

${ }^{21}$ MELLO, Cleyson de Moraes et al. 2016. Artigo 6 ${ }^{\circ}$, III.
} 
A doutrina e jurisprudência afirmam, desde o século XIX, que o dano indenizável é aquele dano que resulta da diminuição das probabilidades de ganho. Assim, o dano derivado da "perda de uma chance" pode impor ao médico a responsabilidade perante o paciente.

\section{DA EUTANÁSIA}

A palavra eutanásia vem de origem grega, onde $e u$ e thanatos significam morte sem sofrimento, sem dor; morte doce. ${ }^{22}$ Foi utilizada, na história, pela primeira vez pelo inglês Frank Bacon. Ele defendia prática da eutanásia, quando não houvesse mais meios de curas, pelos médicos, dos pacientes terminais. ${ }^{23}$ José Ildefonso Bizatto (2000), definiu eutanásia como sendo "aquela morte que alguém dá a outrem que sofre de uma enfermidade incurável, a seu próprio requerimento, para abreviar agonia muito grande e dolorosa". ${ }^{24}$

Eutanásia é tema polêmico, com várias opiniões e entendimentos, as quais devem ser respeitadas, porque, independente do meio aplicado, o resultado é sempre igual: a morte. Assim, pode-se observar o mistério gerado e que, não nos trazem respostas concretas, não passando de apenas inúmeros questionamentos. Talvez, isso aconteça por ao se tratar de morte, o homem se atemoriza e sofre, pois não será possível vencer ou curar enfermidade.

A eutanásia não é uma prática recente da humanidade, podendo ser encontrada já no começo da civilização. Não se pode afirmar com clareza a origem dessas práticas, mas sendo no sentido de morte com piedade, não é tão estranha para população grega, tendo em vista que eles mesmos as nomearam. Em 400 anos a.C., Platão, em Atenas, impunha o sacrifício dos inválidos, buscando fortalecimento do bem-estar da sociedade. Ele, juntamente com Sócrates, afirmava "morte serena". Antes desses dois pensadores, Licurgo ordenava morte dos menores incapazes (aleijados ou débeis), buscando apenas sociedade apta para guerrear. ${ }^{25}$

Os romanos também participavam dessa prática, dando a lei, um tratamento diferenciado a quem a cometia. Era considerada, pelos

\footnotetext{
${ }^{22}$ INTERNET. http://br.monografias.com/trabalhos2/eutanasia/eutanasia.shtml, p. 1.

${ }^{23}$ INTERNET. http://br.monografias.com/trabalhos2/eutanasia/eutanasia.shtml, p. 1.

${ }^{24}$ ILDEFONSO BIZATTO, José. 2000, p. 15.

${ }^{25}$ INTERNET. http://br.monografias.com/trabalhos2/eutanasia/eutanasia.shtml, p. 3.
} 
julgadores, diferente de homicídio, não só na culpa do agente, mas também, para estipular a pena do individuo. Ainda nas civilizações antigas, pode-se inserir os germanos, que matavam aqueles considerados incuráveis; os eslavos e celtas adiantavam a morte dos pais, quando considerados enfermos irreversíveis.

Na Idade Média, com epidemias e pestes que se espalhavam, era comum prática da eutanásia, tendo em vista a miséria da população. No século XX, na Europa, ficou pouco conturbada a concepção de eutanásia, porque a utilizava para "limpeza social", praticando com quem era deficiente e portadores de doenças indesejáveis, buscando perfeição da raça. ${ }^{26} \mathrm{Na}$ Inglaterra, em 1931, foi proposta Lei para legalizar eutanásia, quando foi, em 1936, rejeitada pela Câmara dos Lordes. Durante esses debates foi revelada facilitação, por parte do médico real, na morte do Rei George V, ao aplicarem cocaína e morfina.

A legislação uruguaia, conhecida como a primogênita ao regulamentar esse tema, em 1934 incluiu a possibilidade de eutanásia em suas leis. Já a Igreja Católica, em 1956, anunciou ser contra essa prática. ${ }^{27}$ Já em 1973, uma médica holandesa foi julgada e condenada por homicídio, ao aplicar uma dose letal de morfina em sua mãe; porém, a mãe da profissional havia deixado vários pedidos para que ocasionasse a sua morte. $^{28}$

No Brasil, em 1996, com o projeto de lei $125 / 96,{ }^{29}$ no Senado Federal, foi proposto a possibilidade da eutanásia no país. Esse projeto foi vetado, e portanto, até hoje, eutanásia é proibida no Brasil, sendo equiparada e julgada como homicídio. A Constituição Federal Brasileira, em seu artigo $5^{\circ}$, dispõe sobre os direitos e garantias fundamentais, sendo, então, assegurado o direito à vida e considerado esse, um bem inviolável e indisponível, não tendo o ser humano, portanto, o direito de acabar com a própria vida, já que o Estado a protege desde sua concepção até a morte. A prática de eutanásia não esta explícita no Código Penal Brasileiro, sendo assim, configurada como homicídio, em seu artigo 121: "Matar alguém: Pena - reclusão, de 6 (seis) a 20 (vinte) anos.”, mesmo o agente não tendo a intenção de matar.

\footnotetext{
${ }^{26}$ INTERNET. http://br.monografias.com/trabalhos2/eutanasia/eutanasia.shtml, p. 4.

${ }^{27}$ INTERNET. http://br.monografias.com/trabalhos2/eutanasia/eutanasia.shtml, p. 4.

${ }^{28}$ INTERNET. http://br.monografias.com/trabalhos2/eutanasia/eutanasia.shtml, p. 5.

${ }^{29}$ INTERNET. https://jus.com.br/artigos/4217/a-legalizacao-da-eutanasia-no-brasil/2
} 
A eutanásia possui diversas classificações, fazendo, assim, necessário, uma análise que, aparente ser de melhor e mais fácil compreensão. Pode-se destacar classificação quanto ao consentimento do paciente, a qual pretende analisar a responsabilidade do agente, que nesse caso é o médico. Ela subdivide-se em: 1- eutanásia voluntária: quando a morte foi provocada pela vontade do paciente; 2 - eutanásia involuntária: quando a morte foi provocada sem a vontade do paciente e, 3- eutanásia não-voluntária: quando a morte foi provocada sem que o paciente tenha manifestado alguma vontade;

No Brasil, em 1928, foi proposta uma divisão pelo professor Ruy Santos conforme quem executa a eutanásia: 1- eutanásia-homicídio: quando a eutanásia foi praticada para terminar com a vida de outrem, podendo o autor ser o médico ou algum familiar e, 2- eutanásia-suicídio: quando o próprio paciente executa a ação. Pode ser considerada a ideia precursora de suicídio assistido.

Quando se trata de eutanásia, não se pode pensar apenas em morte, mas também em vida e em dignidade humana. É difícil saber e impor até onde o homem pode dispor da sua vida quando está com doenças incuráveis. Assim, surgem dúvidas nos campos éticos, jurídicos e religiosos. Não é possível compreender e nem se quer julgar o que a morte significa para o outro. Há quem prefira morrer a estar em estado vegetativo, mas por outro lado, há as pessoas que optam por lutar, mesmo que com dor ou até mesmo estando inconscientes. A dignidade trata-se do direito das pessoas de não serem tratadas de qualquer forma, julgado como desrespeito dentro de uma determinada sociedade, ou seja, de não serem tratadas com indignidade. Segundo o autor Lucien Israel:

\footnotetext{
A dignidade humana está sempre acompanhada de perto pelo respeito, pela honra, pela consciência que cada um de nós tem do seu próprio valor enquanto cidadão e ser humano, detentor de uma vida $\mathrm{e}$ de uma individualidade, bem como portador de características únicas que fazem dele um ser sem igual. A dignidade humana comporá também, no seio da sua essência, os valores de uma sociedade. No entanto, e no caso e um ser humano em estado terminal que peça a Eutanásia, a sua dignidade passa pelo direito a ser tratado como qualquer ser humano saudável e não a ser tratado como se já estivesse sem vida. (ISRAEL, 1993, p. 59)
}

Assim, o direito à dignidade deve ser garantido não somente às pessoas fisicamente e mentalmente debilitadas, mas também aos parentes e pessoas ligadas ao paciente. 


\section{ASPECTOS JURÍDICOS}

A eutanásia é um tema muito polêmico, gerando muitos posicionamentos a respeito da sua prática. Deve-se considerar o direito à vida como o mais importante dos direitos que estão assegurados pela Constituição Federal Brasileira como uma garantia fundamental. A vida deve ser protegida de todas as ameaças que tenham por fim violá-la. O ordenamento jurídico brasileiro prevê esta garantia e tem por objetivo preservar a vida de tudo que atente contra esse direito. Assim, o direito à vida deve ser protegido pelo Estado. A partir do momento que o médico causar danos ao paciente, através de suas práticas, deverá ser responsabilizado civil, penal e eticamente.

A eutanásia, no direito brasileiro, é enquadrada como homicídio privilegiado, no art. $121, \S 1^{\circ}$ do Código Penal Brasileiro, ou seja, lei prevê redução na pena de um sexto a um terço caso: "se agente comete o crime impelido por motivo de relevante valor social ou moral, ou sob o domínio de violenta emoção, logo em seguida a injusta provocação da vitima." Então, a prática de eutanásia no Brasil é considerada crime, mesmo quando o doente pede para morrer, porque não aguenta mais sofrer, passando por muitas dores e momentos de angústia, vendo a morte se aproximar lentamente. Apenas a eutanásia passiva, a qual é a forma que "deixa-se morrer" não é tipificada como crime, porque deixa o paciente em estado terminal morrer, não prolongando seus sofrimentos, sabendo ser inúteis os meios para mantê-lo vivo, em estado vegetativo. Portanto, não há motivo para manter alguém vivo, com auxílios de aparelhos médicos, quando se afirma não ter mais possibilidade de uma vida normal para o paciente, só aumentando, assim, o sofrimento dele e da família.

E, após toda essa análise, a eutanásia é, portanto, um fato muito discutido nos dias atuais, levantando a indagação de até quando o homem pode decidir sobre a própria vida, ou seja, até onde os valores éticos, morais e religiosos podem influenciar na vida de um paciente terminal. Assim, não consiste apenas em uma questão bioética, envolvendo toda a sociedade e os demais segmentos nela contida. Não é uma questão recente, já existente nos primórdios da existência humana. Porém, sempre que colocada em pauta, causa grandes duvidas. Encontrar um único conceito para a 
eutanásia é muito difícil, já que, ao defini-la, os autores utilizam de suas concepções éticas, morais e religiosas, variando, portanto, de individuo para individuo. Pode-se dizer que é a privação da vida de uma pessoa, considerada paciente terminal, ao desejar fim do sofrimento e da dor. Assim, pode-se afirmar que é a morte antes de seu tempo.

O direito à vida é indispensável para a prática e a aquisição de todos os outros direitos, sendo, então, protegido pela Constituição Federal Brasileira. A eutanásia, porém, ameaça esse direito tão precioso. Da mesma forma que é direito do homem de viver, é direito, também, morrer, a partir do momento que já não tem mais chances de se ter uma vida digna. A dignidade também é um direito amparado pela Constituição Federal, sendo um dever do Estado amparar o ser humano para que assim, obtenha-se esse direito fundamental.

O médico, ao exercer sua atividade, deve sempre se basear na Bioética, objetivando o verdadeiro fim da Medicina. Deve-se considerar o consentimento, a opinião do paciente, ou o de algum familiar quando este não puder responder. É dever do medico também buscar sempre o melhor para o bem estar de seu paciente. É fundamental que o médico mantenha a família e o paciente informados sobre os processos ministrados. Ética e moralmente, não é aceitável que não se ministre medicamentos ao paciente, deixando-o morrer.

O Código Penal Brasileiro não admite a morte provocada por piedade. Então, ao causar danos ao paciente, o médico deverá ser responsabilizado nas esferas cíveis, penais e/ou éticas. E, ao praticar eutanásia, comprovado o dano, devera reparar os seus atos. O presente trabalho não teve intenção de se portar contra ou a favor da eutanásia, estudo esse justificado pela sua atualidade, não obtendo assim, uma solução definitiva quanto à essa prática, mas apenas uma possível compreensão mais clara suas implicações.

\section{REFERÊNCIAS BIBLIOGRÁFICAS}

AGUIAR DIAS, José de. Da responsabilidade civil. 4. ed. Rio de Janeiro: Forense; 10. ed., 1997.

ALVIM, Agostinho. Da inexecução das obrigações e suas consequiências. $3^{a}$. ed. Ed. Jurídica e Universitária. 1966. 
BIZZATO, José Ildefonso. Eutanásia e responsabilidade médica. 2. Ed., São Paulo: Editora de Direito, 2000.

CARVALHO, Jose Carlos Maldonado de. Responsabilidade civil médica. Rio de Janeiro: Destaque, 2002.

CROCE, Delton. Erro médico e direito. São Paulo: Saraiva, 2002.

CAVALIERI FILHO, Sergio. Programa de responsabilidade civil. São Paulo: Atlas, 2015.

Faria B de. Anotações theórico-práticas ao código penal do Brasil. 4.ed. 1929: 523.

GONÇALVES, Carlos Roberto. Direito civil brasileiro. São Paulo: Saraiva, 2017.

INTERNET. http://br.monografias.com/trabalhos2/eutanasia/eutanasia.shtml

INTERNET.https://jus.com.br/artigos/4217/a-legalizacao-da-eutanasia-no-brasil/2

ISRAEL, Lucien. O argumento da dignidade humana. 1993.

KUHN, Maria Leonor de Souza. Responsabilidade civil: a natureza jurídica da relação médico-paciente. Tamboré: Manole, 2002.

MACHADO, Costa et al (Org.). Código civil interpretado. Barueri: Manole, 2016.

MEDINA, Jose Miguel Garcia. Constituição federal comentada. São Paulo: Revista dos Tribunais, 2014.

MELLO, Cleyson de Moraes et al. Código de defesa do consumidor comentado. São Paulo: Freitas Bastos, 2016.

RESENDE, Denise Andréa Lima. A eutanásia: em busca de sua legitimação no estado democrático de direito. Dissertação de Mestrado. Universidade FUMEC. Programa de pós graduação em Direito. Belo Horizonte. 2007.

SILVA, Wilson Melo da. Responsabilidade sem culpa e socialização do risco. Belo Horizonte: Ed. Bernardo Álvares, 1962.

STOCO, Rui. Tratado de responsabilidade civil: doutrina e jurisprudência. São Paulo: Revista dos Tribunais, 2014.

SARAIVA, Editora. Mini Código Saraiva Penal 2017: Constituição Federal E Legislação Complementar. Ed. Saraiva, 2017. 
ZAIDHAFT, Sergio. Morte e formação médica. Rio de Janeiro: Francisco Alves, 1990.

CONSELHO FEDERAL DE MEDICINA. Resolução n.1.805/2006. Brasília: CFM, 2006. Disponível em:

http://www.portalmedico.org.br/resolucoes/cfm/2006/1805_2006.htm. Acesso em: 20 de março de 2017.

Da responsabilidade civil do médico - a culpa e o dever de informação. Artigo publicado no site Portal Conteúdo Jurídico, em 31 de maio de 2010. Disponível em http://www.conteudojuridico.com.br/?colunas\&colunistas=151_Mariana_Pretel\&ver=641 ISSN - 1984-0454. 